Sustainable Structures

ISSN: 2789-3111 (Print); ISSN: 2789-312X (Online)

http://www.sustain-dpl.com/picnews.asp?id=155

DOI: $10.54113 /$ j.sust.2022.000013

ORIGINAL ARTICLE

\title{
Mechanical behavior analysis of LEM-infilled cold-formed steel walls
}

\author{
Wanqian Wang a, ${ }^{\text {, }}$ Jingfeng Wang ${ }^{\text {a, }}{ }^{*}$, Lei Guo ${ }^{\text {a }}$ \\ ${ }^{a}$ School of Civil Engineering, Hefei University of Technology, Anhui Province, 230009, China \\ ${ }^{b}$ Anhui Key Laboratory of Civil Engineering Structures and Materials, Anhui Province, 230009, China \\ c Anhui Collaborative Innovation Centre of Advanced Steel Structure Technology, Anhui Province, 230009, China \\ *Corresponding Author: Jingfeng Wang. Email: jfwang008@ 163.com.
}

\begin{abstract}
The sustainable development of the engineering structures mainly depends on the environmental- friendly to structural components. This requires the development of sustainable and new materials and structures that would be a worthy alternative for the available. This paper proposed a novel type of cold-formed steel (CFS) shear wall which filling light EPS mortars (LEM) into the space of CFS framing. LEM-infilled CFS walls carry forward the merits of traditional CFS wall, for example lightweight, easy installation, superior earthquake resistance and efficient energy saving. Moreover, employing recycled desulfurization gypsum and EPS in the structural materials reduce environmental pollution. However, the behavior of LEMinfilled CFS wall is not fully explored yet, which results in the low understanding and application of the material around the world. Based on this background, a review of mechanical response tests will contribute to a better awareness. In this paper, three types of mechanical behaviours are discussed including axial compressive behaviour, out-of-plane flexural behaviour, and cyclic behaviour. The previous researches on the mechanical performance of LEM-infilled CFS walls were reviewed. And the typical failure patterns and general results were described and discussed. This work will provide an excellent reference to current practice and future exploration.
\end{abstract}

Keywords: LEM-infilled CFS wall; mechanical behaviour; axial compressive test; out-of-plane flexural test; cyclic test

\section{Introduction}

The rapid development of China's infrastructure costs a lot of resources and energies and brings serious problems such as resources, energy shortage, and environmental degradation. Against this situation, the policies of energy conservation, emission reduction and sustainable development come into being. As an important part of energy consumption, the construction industry has attracted more and more attention. Currently, interest in cold-formed structure (CFS) structure deriving from the wood structure is growing due to its easy installation, energy-saving, and environmental-friendly. However, huge contrast is found between Chinese architectural tradition preferring solid walls and the hollow characteristic of CFS structures. In order to make up for the shortcomings of the traditional CFS structure and meet the requirements of sustainable development at the same time, a new type of lightweight mortars infilled CFS structure is proposed [1-3]. The research group of Prof. Wang in the Hefei University of Technology introduced a lightweight mortar, using desulfurization gypsum and expanded polystyrene (EPS) as main ingredients, into CFS walls [4-6]. The lightweight mortar wall was

$000013-1$

Received: 6 October 2021; Received in revised form: 26 January 2022; Accepted: 1 February 2022 This work is licensed under a Creative Commons Attribution 4.0 International License. 
called LEM in brief. Fig. 1 shows the application of LEM-infilled CFS walls in Anhui Province, China. It can be seen that the LEM-infilled CFS walls have been highly applied to rural residences and tourist buildings.

In response to the needs of social development, plenty of EPS are used and the total amount of wasting EPS increase sharply. While, the EPS are a type of hard-degradable material so that it causes great pollution to the environment around the whole world in accordance with the statistics [8]. Many researchers found that using EPS as an alternative to coarse aggregate in concrete could improve heat preservation and thermal insulation performance [9-13]. Besides, it could also solve the environmental problem of "white pollution" caused by plastic foam waste. Therefore, it is very important to EPS recycling. In recent years, the concept of sustainable development has attracted people's attention. Thus, employing waste EPS into structural mortars can not only improve the original performance of mortars, but also reuse waste EPS to achieve a "win-win".
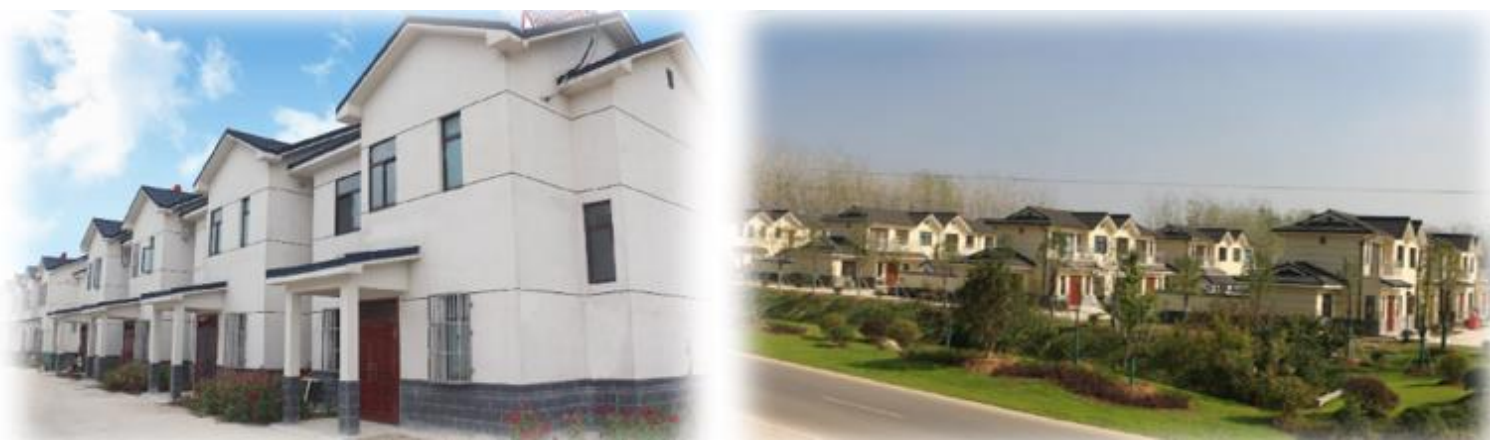

(a) Rural residences
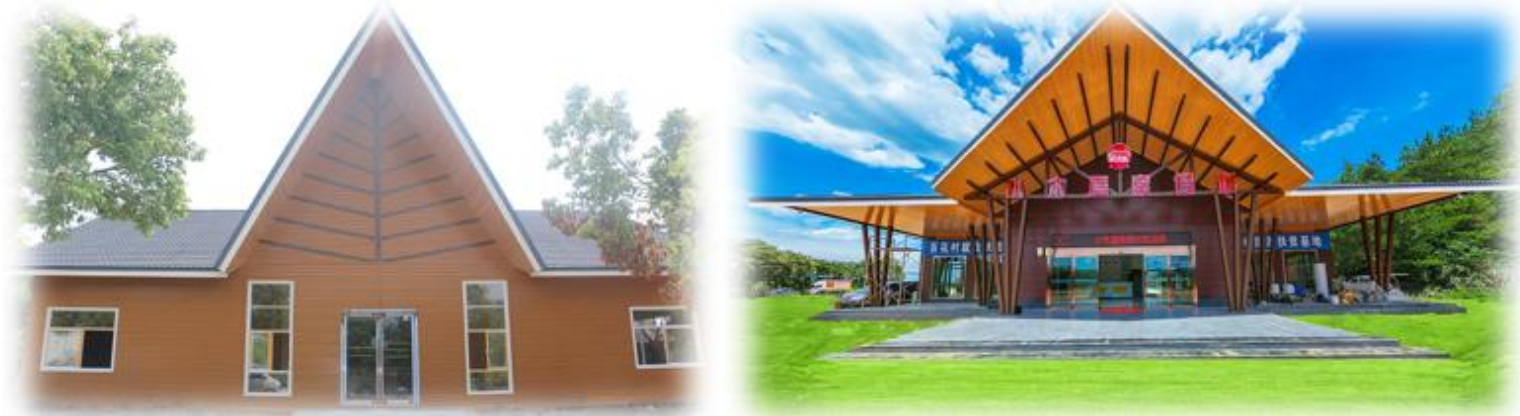

(b) Visitors' Centers of resorts

Fig. 1 Structures made by LEM-infilled CFS walls

As one of the conventional cementitious materials, gypsum has a long history of application in civil engineering. China has abundant gypsum resources, and the reserves of natural gypsum occupy the first place in the world. Moreover, with the continuous development of the economy, the amount of industrial by-product gypsum also increases with the passage of time. The annual discharge amount of industrial by-product gypsum in China is more than 70 million tons, but the utilization rate is low. This results in a large number of wastes all year round, which not only occupies space land, but also pollutes soil and groundwater seriously. The desulfurization gypsum is a kind of industrial by-product gypsum, which exhibits high quality and fewer impurities. It makes desulfurization gypsum has great potential application value [14-17].

The LEM used in this paper employs desulfurization gypsum as the main cementitious material, and utilizes recycled EPS as lightweight aggregate. The application of LEM can make full use of industrial by-products and promote sustainable development. The LEMs are cast in the space of CFS walls to improve their sound insulation, thermal insulation and heat-shielding performance. Unlike conventional CFS hollow walls, the studs in infilled walls were not only braced by sheathings, but also wrapped by filling materials. In spite of the available mechanical behavior of the traditional CFS wall studs being well understood [18-23], there were significant distinctions between the design of the CFS wall stud and the stud encased in lightweight mortars under various types of loading. 
Against this, the research group of Prof. Wang carried out a series of tests to evaluate the mechanical behaviours of the LEM-infilled CFS walls. This paper has the purpose to exhibit a series of mechanical behaviour tests and analyses. The research results would serve as a reasonable reference to design the new LEM-infilled CFS wall, and promote the process of sustainable structures.

\section{Detail of LEM-infilled CFS walls}

\subsection{Lightweight expanded polystyrene mortars}

The lightweight expanded polystyrene mortars are classified into cement-based and gypsum-based materials in accordance with different cementitious materials. Table 1 lists the main mix proportion of LEM.

Table 1. Mix proportion of LEM

\begin{tabular}{ccccccccc}
\hline LEM & $\begin{array}{c}\text { Cement } \\
\left(\mathrm{kg} / \mathrm{m}^{3}\right)\end{array}$ & $\begin{array}{c}\text { EPS } \\
\left(\mathrm{m}^{3}\right)\end{array}$ & $\begin{array}{c}\text { Gypsum } \\
\left(\mathrm{kg} / \mathrm{m}^{3}\right)\end{array}$ & $\begin{array}{c}\text { Retarder } \\
\left(\mathrm{kg} / \mathrm{m}^{3}\right)\end{array}$ & $\begin{array}{c}\text { Expansive agent } \\
\left(\mathrm{kg} / \mathrm{m}^{3}\right)\end{array}$ & $\begin{array}{c}\text { Additive } \\
\left(\mathrm{kg} / \mathrm{m}^{3}\right)\end{array}$ & $\begin{array}{c}\text { Fly ash } \\
\left(\mathrm{kg} / \mathrm{m}^{3}\right)\end{array}$ & $\begin{array}{c}\text { Water } \\
\left(\mathrm{kg} / \mathrm{m}^{3)}\right.\end{array}$ \\
\hline $\begin{array}{c}\text { Gypsum- } \\
\text { based }\end{array}$ & - & 0.75 & 450 & 2.0 & - & 2.0 & - & 275 \\
$\begin{array}{c}\text { Cement- } \\
\text { based }\end{array}$ & 300 & 0.6 & - & - & 125 & 2.0 & 65 & 225 \\
\hline
\end{tabular}

Table 2. Material properties of LEM

\begin{tabular}{ccccc}
\hline Type & $\begin{array}{c}\text { Dry apparent } \\
\text { density }\left(\mathrm{kg} / \mathrm{m}^{3}\right)\end{array}$ & $\begin{array}{c}\text { Elastic modulus } \\
(\mathrm{MPa})\end{array}$ & $\begin{array}{c}\text { Compressive strength } \\
(\mathrm{MPa})\end{array}$ & $\begin{array}{c}\text { Thermal conductivity } \\
\mathrm{W} /\left(\mathrm{m}^{2} \cdot \mathrm{K}\right)\end{array}$ \\
\hline $\begin{array}{c}\text { Cement-based LEM } \\
\text { Gypsum-based }\end{array}$ & 456 & 250 & 2.1 & 0.051 \\
LEM & 449 & 200 & 1.1 & 0.053 \\
\hline
\end{tabular}

In terms of the cement-based LEMs, polystyrene beads were used as lightweight aggregate, which had specific gravity, bulk density and average diameter of $0.016,16.6 \mathrm{~kg} / \mathrm{m}^{3}$ and $6.5 \mathrm{~mm}$, respectively. And the low calcium fly ash and type 425 ordinary Portland cement are utilized to enhance the workability, cut cost and long-term strength [24]. The crack resistance of LEM can be improved especially by employing the employment of expansive agents. And the expansive agent utilized was calcium sulphoaluminate.

The gypsum-based LEMs are consisted of incorporating the gypsum, EPS, retardants, water and additives. The retarders are added with the purpose of postponing the fast setting time of the gypsumbased LEM. This paper used the gypsum retarder sodium polyphosphate. In addition, the properties of the LEM are subjected to alteration by changing the light admixture amount.

Several material tests [5] have been carried out to obtain the properties of LEMs, and the cubic specimens, prism specimens and plate specimens are prepared to measure the Elastic modulus, compressive strength and thermal conductivities, respectively. The stress-stain curves of prism specimens under compressive load were used to determine the elastic modulus. Table 2 lists the test results of material properties. Besides, the tensile strength of LEM is obtained through compressive strength, based on the empirical formulas summarized by the previous researches [25-26]. The results indicated that LEMs exhibited significant thermal properties, with respect to other filling materials employed in CFS walls such as foamed concrete [27-28]. Thus, LEMs is a good selection for insulation material and structural bearing in green building.

\subsection{Configuration}

The general production process of CFS wall filled with LEM approximately has 6-step, as depicted in Fig. 2.

Step 1: The CFS tracks and studs are inherited from the conventional CFS framing wall, which mainly bears the axial compressive load. During construction, the CFS framing also plays as a pouring formwork of the LEM. 
Step 2: The X-shaped bracings are attached to both sides of CFS framings (if needed) using selfdrilling screws.

Step 3: The wall panel are connected to the side of CFS framings using self-drilling screws. The self-drilling screws spaced at $150 \mathrm{~mm}$ along the perimeter, and $300 \mathrm{~mm}$ in the interior area. And the sheathed side would be placed at the bottom, so that the wall panels act as the construction formwork of LEM spraying.

Step 4: The LEMs are casted into the space of the CFS framing. The LEMs worked together with CFS framing can resist both shear and axial loads, which can also increase the load-bearing capacities of the studs. The responses of CFS framing-wall sheathing connection can also be strengthen by the LEM. Moreover, the LEM is of advantage to the thermal performance and acoustic insulation of the wall.

Step 5: The rib laths are fixed on the other side of the CFS framing.

Step 6: An additional $25 \mathrm{~mm}$ thick LEM layer is sprayed on the outside of the rib lath. And the rib lath and the LEM layer work as a whole, called rib lath sheathing.

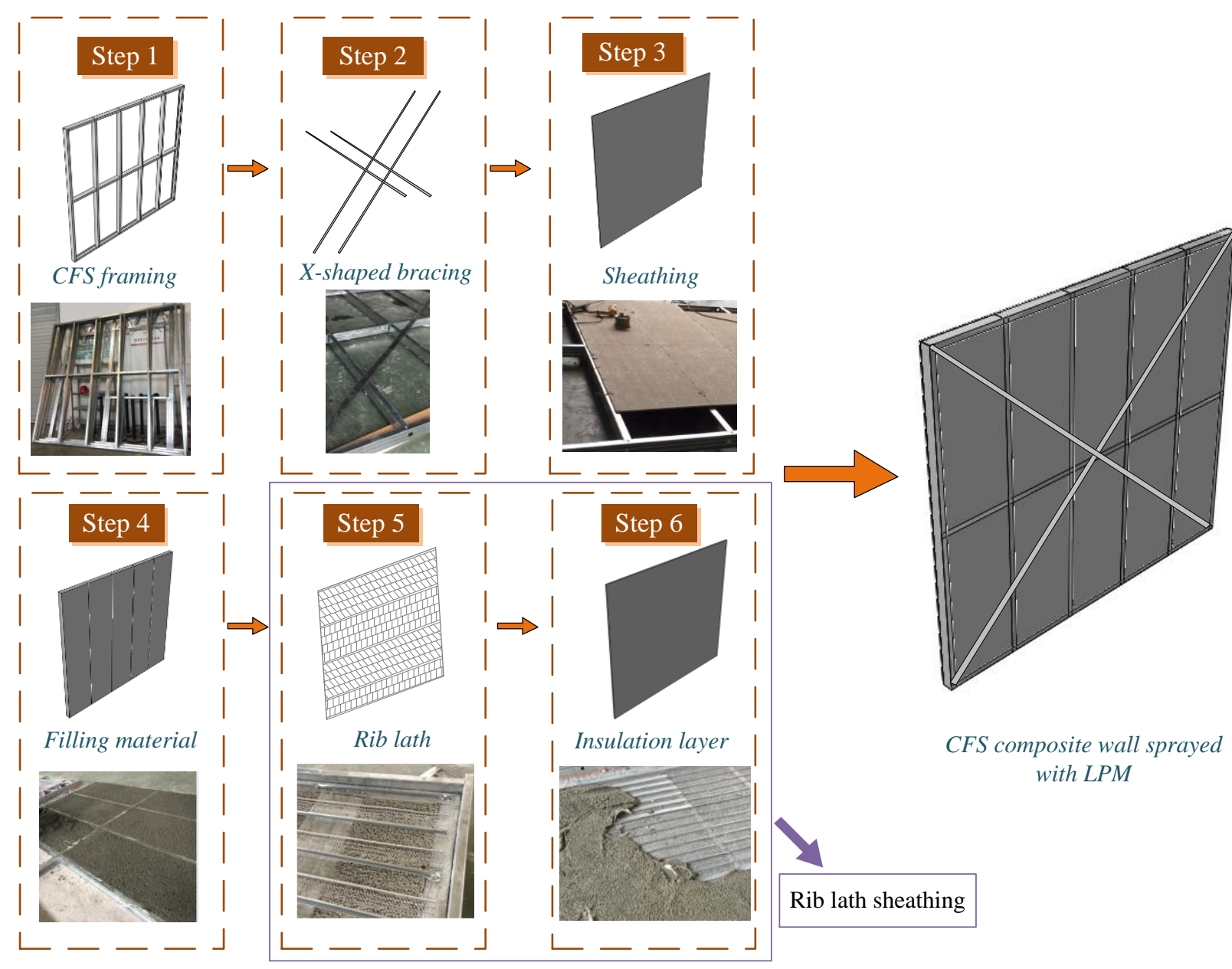

Fig. 2 Production process of LEM-infilled CFS walls

\section{Axial compressive behaviour of LEM-infilled CFS walls}

\subsection{Test specimen}

In an attempt to study the axial compressive behaviours of LEM-infilled CFS walls, five specimens had been designed and tested [6], with the uniform geometrical size of $1.2 \mathrm{~m}$ width and $2.7 \mathrm{~m}$ height. The specimens' detail information is illustrated in Figs. 3 and 4. The specimens took the effect of LEM type and sheathing type into account. Specimens CW1, CW3 and CW5 are gypsum-based LEM filled 
CFS walls, and specimen CW2 and CW4 are CFS walls filling with cement-based LEM. The specimens' tracks were respectively fixed to beams by three M16 $\times 190 \mathrm{~mm}$ bolts. During the construction of LEM, the hold-down and M16 $\times 190 \mathrm{~mm}$ anchor bolts were embedded in advance. Fix the specimens to the test setup by anchor bolts, as shown in Fig. 5. And the arrangement of hold-down is depicted in Fig. 6.

The CFS framings were formed using Galvanised steel components which had a thickness of 0.9 $\mathrm{mm}$ and a nominal strength of 550MPa. Tensile tests were conducted to measure the material properties, and the yield strength, Elastic modulus, tensile strength and elongation of the CFS components were $2.06 \times 10^{5} \mathrm{MPa}, 615 \mathrm{MPa}, 692.5 \mathrm{MPa}$ and $10.6 \%$, respectively. The CFS components used in the outof-plane flexural test and seismic test are the same as the compressive test.

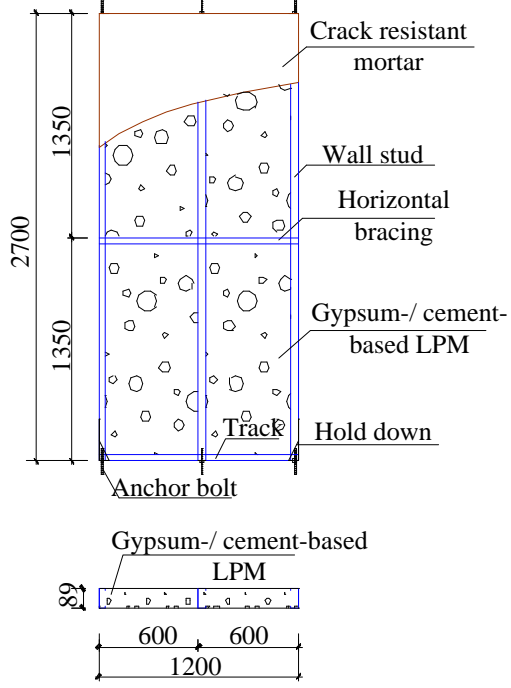

(a) Specimen CW1/CW2

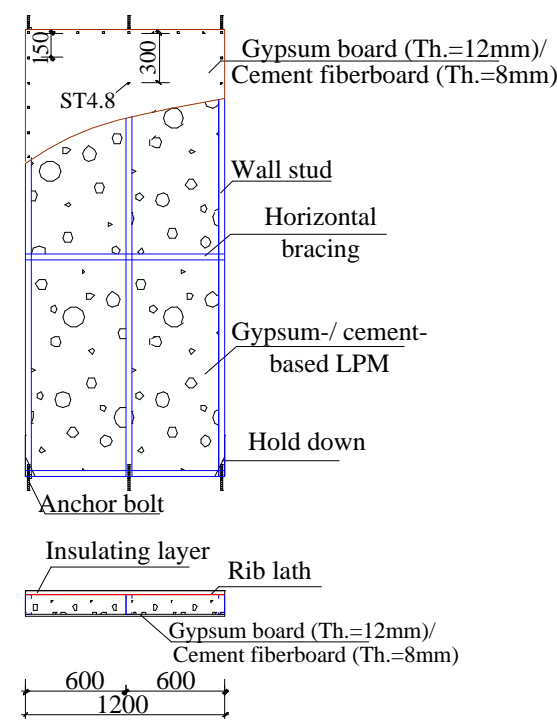

(b) Specimen CW3/CW4
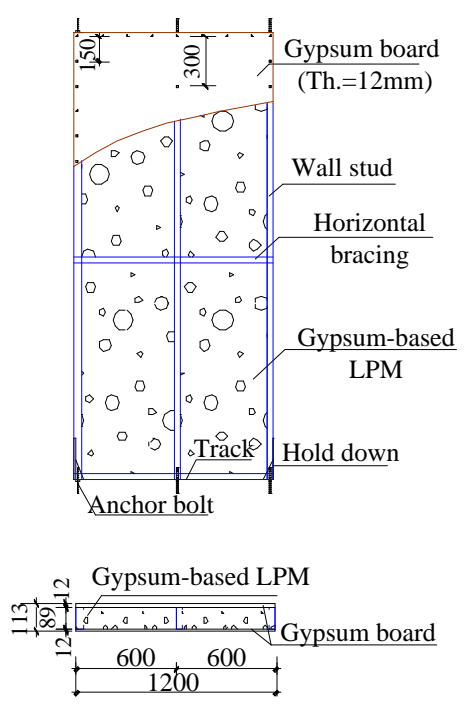

(c) Specimen CW5

Fig. 3 Configuration of specimens [6].

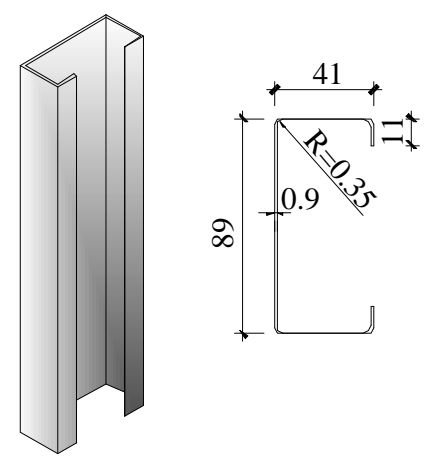

Wall stud
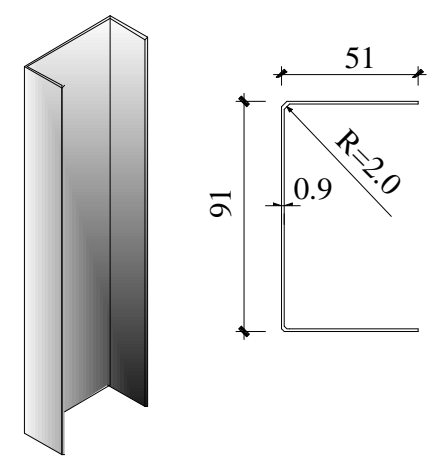

Track

Fig. 4 Cross dimensions of wall stud and track.

\subsection{Test setup and procedure}

During the loading procedure, each $0.1 N_{\text {ue }}$ was imposed to the bottom of the specimen and was held for 3 minutes; in which $N_{\text {ue }}$ was the ultimate axial compressive capacity of the specimens simulated by finite element analysis.

\subsection{Test results}

Regarding for specimens CW1 and CW2 without wall sheathings, the failure modes of the LEMinfilled CFS walls imposed to axial compression loads mainly include LEM cracking, LEM crushing, and wall studs buckling. Other specimens showed similar failure patterns with specimens CW1 and CW2 approximately, except for loosening of the self-drilling screws connection, and cracking and 
shedding of the wall sheathing. Besides, it can be found that wall sheathing can delay the buckling of wall studs. The typical failure patterns of specimens are illustrated in Fig. 7.

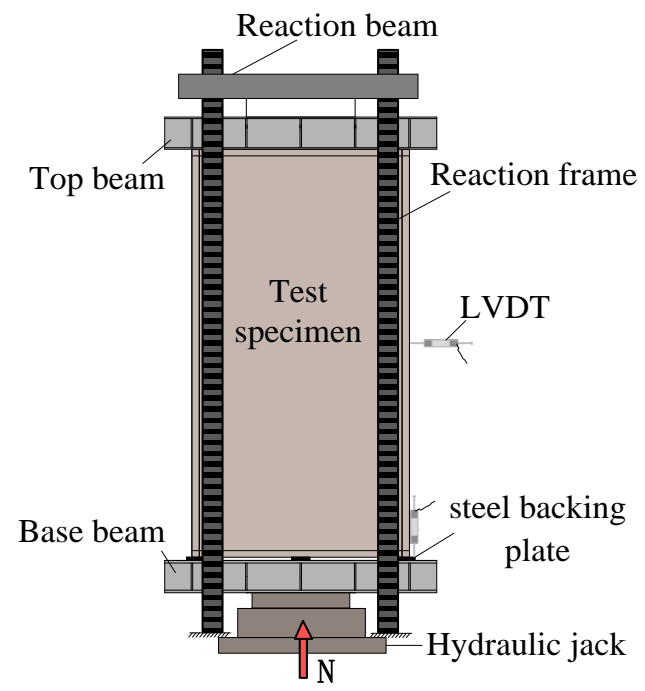

Fig.5 Test setup

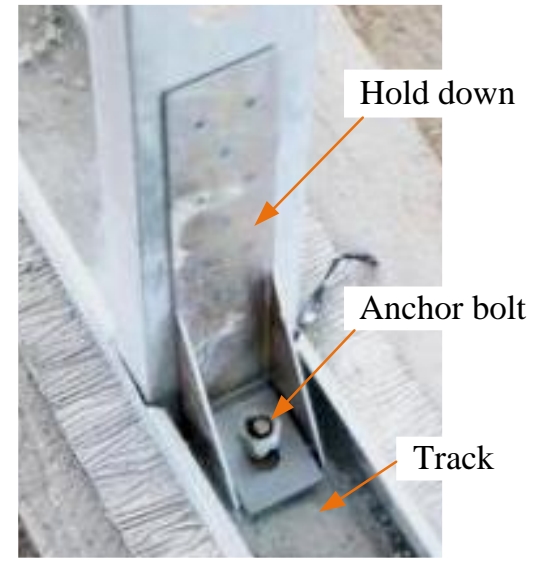

Fig.6 Arrangement of hold down [6].
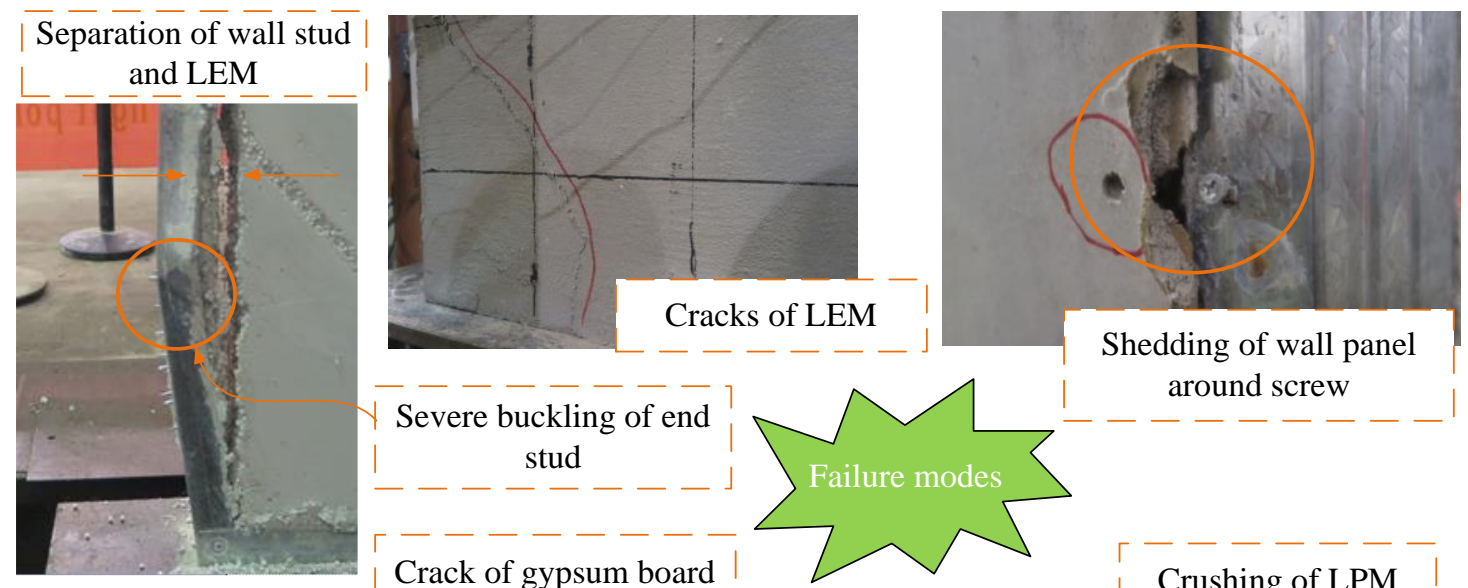

Severe buckling of end stud

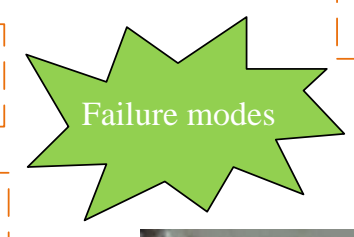

Crack of gypsum board
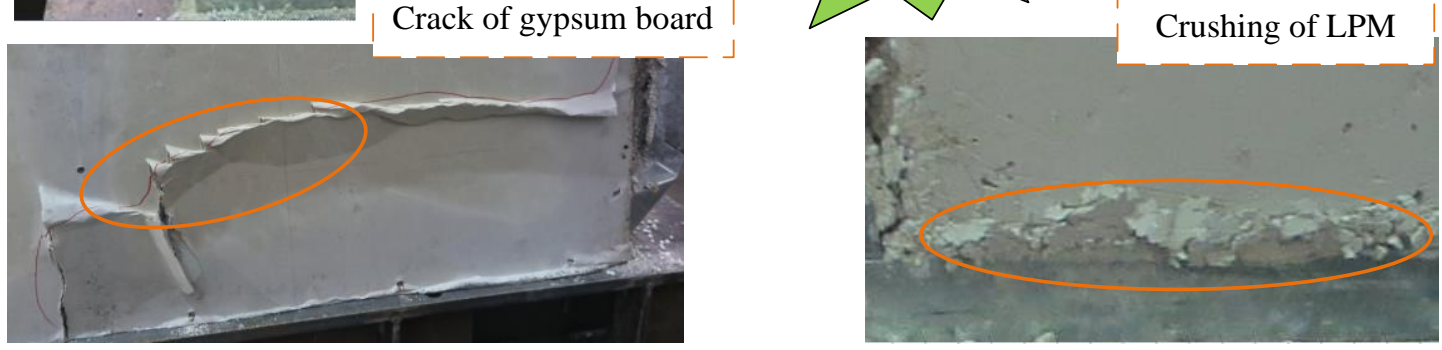

Fig. 7 Failure modes of specimens under axial compressive loads.

The axial load-displacement relationships are showed in Fig. 8. Compared with traditional CFS walls without filling materials, this type of wall showed an excellent axial compressive response. The results indicated that the ultimate load of cement-based LEM- infilled CFS walls (CW2 and CW4) were $56 \%$ 70\% larger than gypsum-based LEM infilled CFS walls (CW1 and CW3). The comparison results also demonstrated that sheathed CFS wall had obvious superiorities, especially employing the rib lath sheathings. It could be seen that the ultimate load of the specimens CW3 and CW4 were 48\% and $62 \%$ larger than that of the specimen CW1 and CW2, respectively. Besides, with respect to CW1, the ultimate strength of the specimen CW5 was only raised by $8 \%$ owing to the weak performance of self-drilling connections between the CFS framing and gypsum board.

Previous studies on traditional CFS wall under compression mainly concentrated on the impact of fastener and sheathing to the wall stud, and considered the effect of sheathing on elastic stability of the 
stud in distortional, local, and global buckling modes [29-31]. Regarding the LEM-infilled CFS wall, the deformation of the wall stud was mainly affected by the warping of filling materials. Besides, the existence of filling materials may decrease the important proportion of fastener and sheathing to the CFS framing. Therefore, the compressive strength design of LEM-infilled CFS wall should take this factor into account.

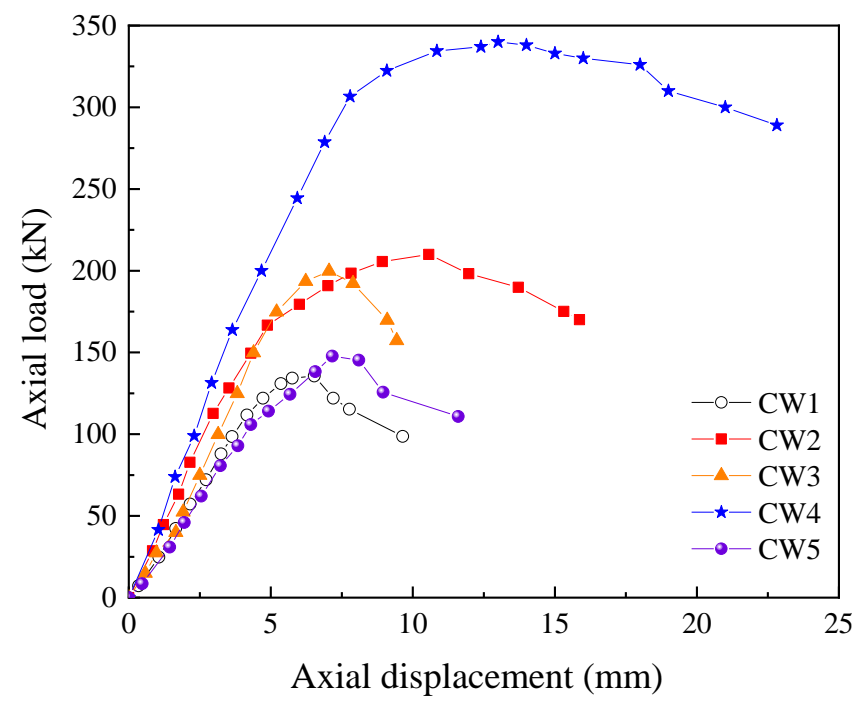

Fig. 8 Axial compressive load-displacement curves [6].

Table 3. Parameters of specimens

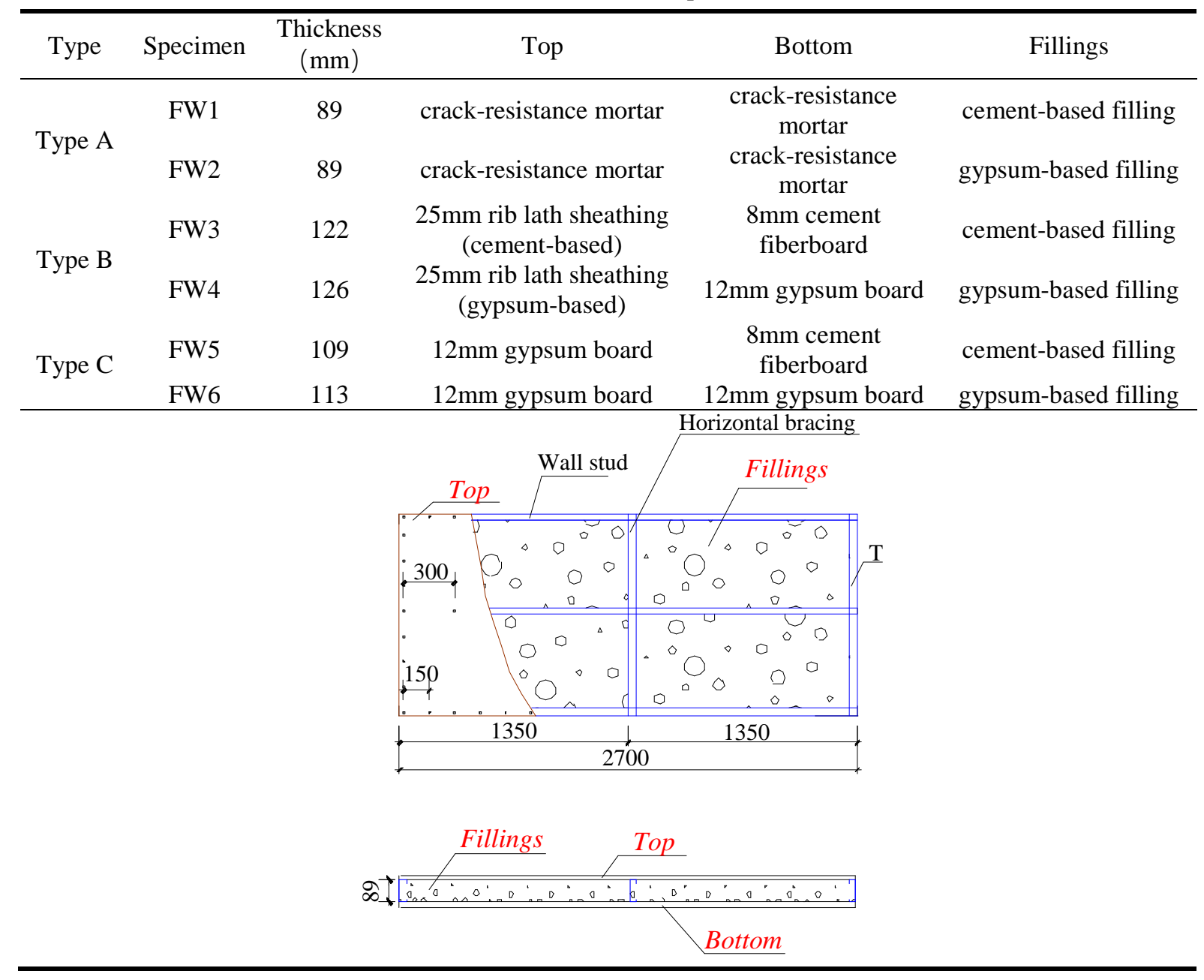




\section{Out-of-plane flexural behaviour of LEM-infilled CFS walls}

\subsection{Test specimen}

Six specimens were tested to explore the out-of-plane flexural behaviour of LEM-infilled CFS walls. All the specimens were manufactured with a size of $1.2 \mathrm{~m}$ width and $3.0 \mathrm{~m}$ height. The configuration and cross-section details are illustrated in Table. 3.

\subsection{Test setup and procedure}

During the tests, specimens were simply supported, subjected to uniformly distributed loads. Sand bags ( $9 \mathrm{~kg}$ per bag) were loaded manually on each specimen of $0.35 \mathrm{kN} / \mathrm{m}^{2}$ with 14 bags in each layer. Fig. 9 illustrates the diagram and photograph of test setup.

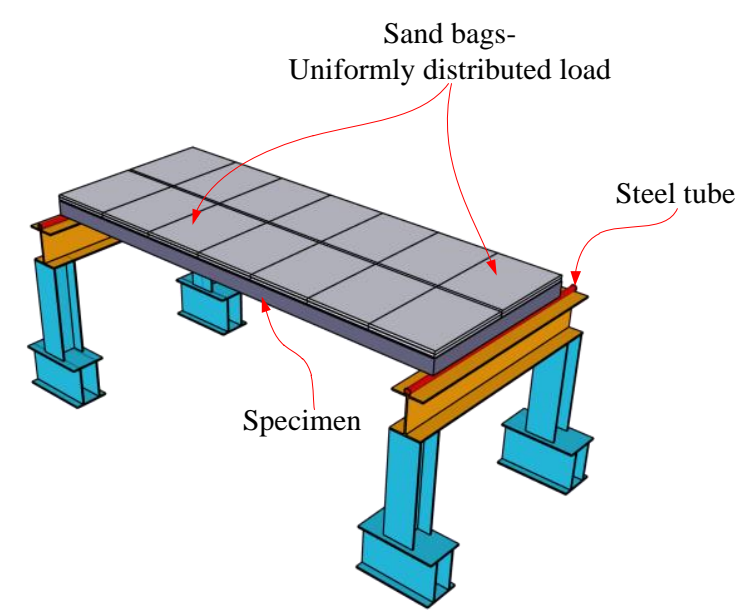

(a) Diagram

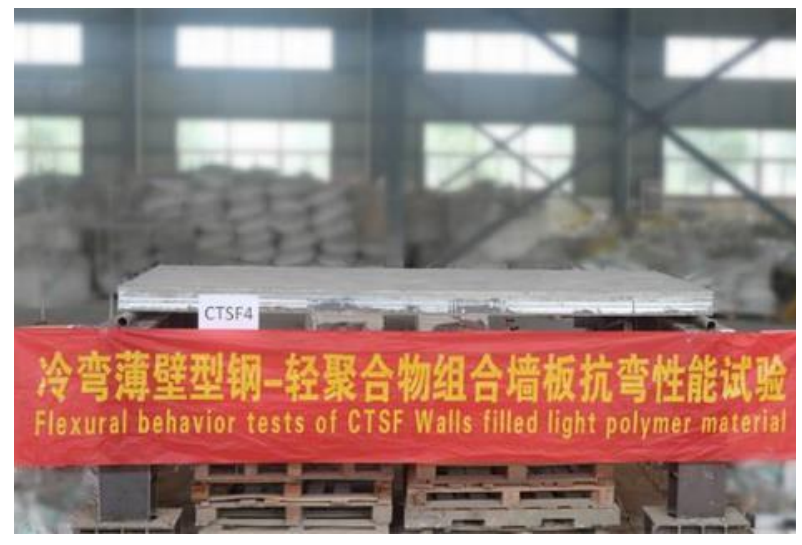

(b) Photograph

Fig. 9 Test loading setup
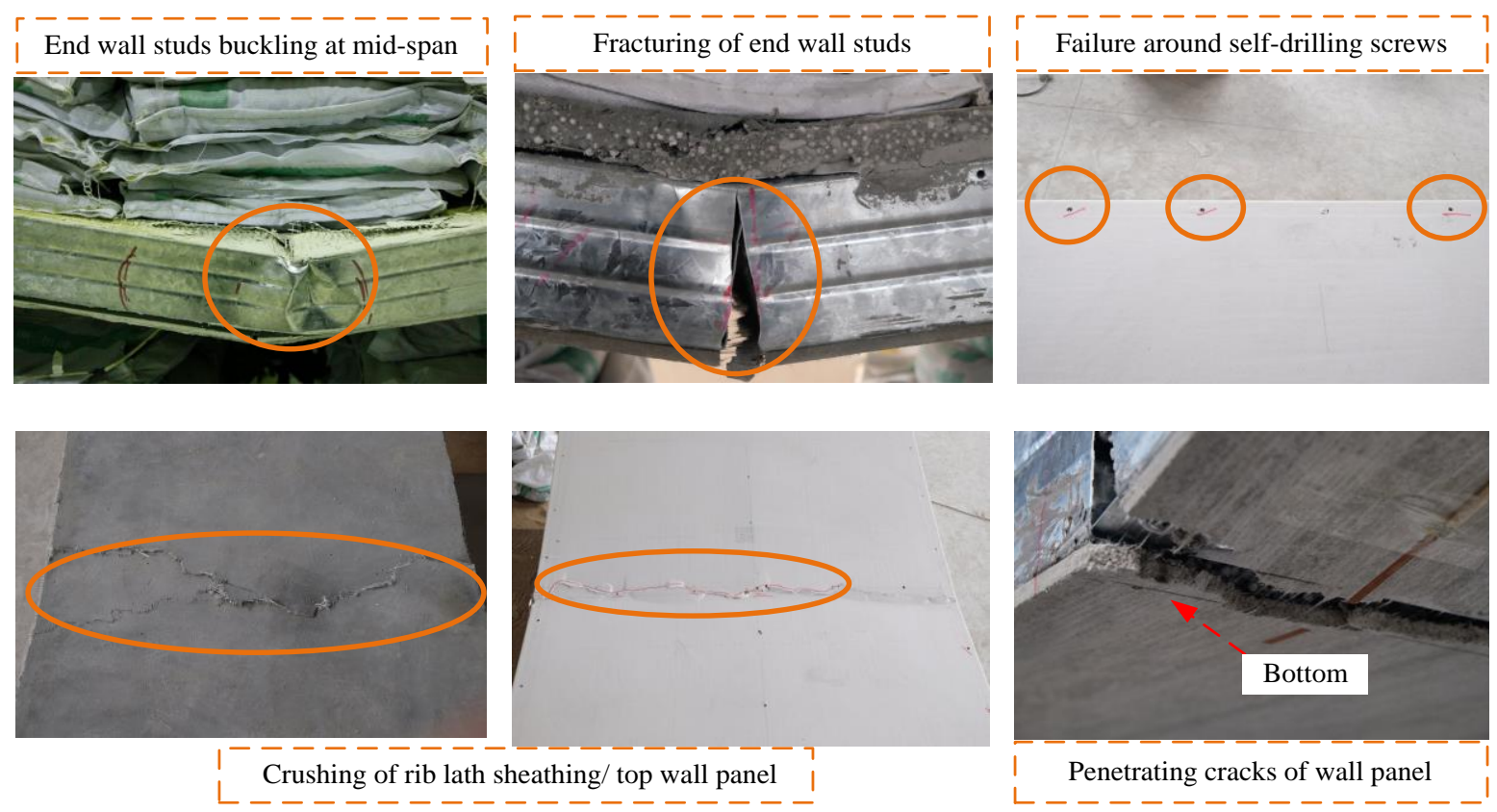

Fig. 10 Failure modes of specimens under uniformly distributed loads

\subsection{Test results}

The general failure modes included severe buckling/ fracturing of end studs at mid-span, failure of wall panel around self-drilling screws, crushing of rib lath sheathing/ top wall panels and penetrating 
cracks of wall panels, as depicted in Fig. 10. The typical failure patterns are illustrated in Table 4. The test phenomenon demonstrated that the sheathing could resist the deformation of wall studs and delay the occur of buckling.

Table 4. Failure modes of each specimen

\begin{tabular}{cc}
\hline Specimens & Failure patterns \\
\hline FW1 and FW2 & $\begin{array}{c}\text { severe buckling/ fracturing of end studs at mid-span } \\
\text { severe buckling/ fracturing of end studs at mid-span } \\
\text { crushing of rib lath sheathing }\end{array}$ \\
& penetrating cracks of bottom wall panels \\
& severe buckling/ fracturing of end studs at mid-span \\
failure of top wall panel around self-drilling screws & crushing of top wall panels \\
& penetrating cracks of bottom wall panels \\
\hline
\end{tabular}

The relationships between the deflection and load at the mid-span of LEM-infilled CFS walls and the deflection before failure are illustrated in Fig. 11. All specimens experienced three stages including the linear elastic, yielding and ultimate failure stage. Compared with gypsum-based LEM infilled walls, the elastic stiffness and ultimate strength of cement-based LEM infilled walls were obviously higher. It can be explained by the fact that the cement-based LEM had larger compressive strength and elastic modulus. Undoubtedly, wall sheathing could restrict the deformation of the specimen and improve the capacity, which can be improved by the fact that the ultimate strength of the specimen FW3 and FW5 were respectively $69.23 \%$ and $38.46 \%$ higher than that of the specimen FW1. The shapes of curves were symmetrical and the maximum deflection value gradually appeared in the mid-span before failure. According to the calculation, it could be known that the flexural bearing capacities of the specimens were 9.69-13.14 times their self-weight.

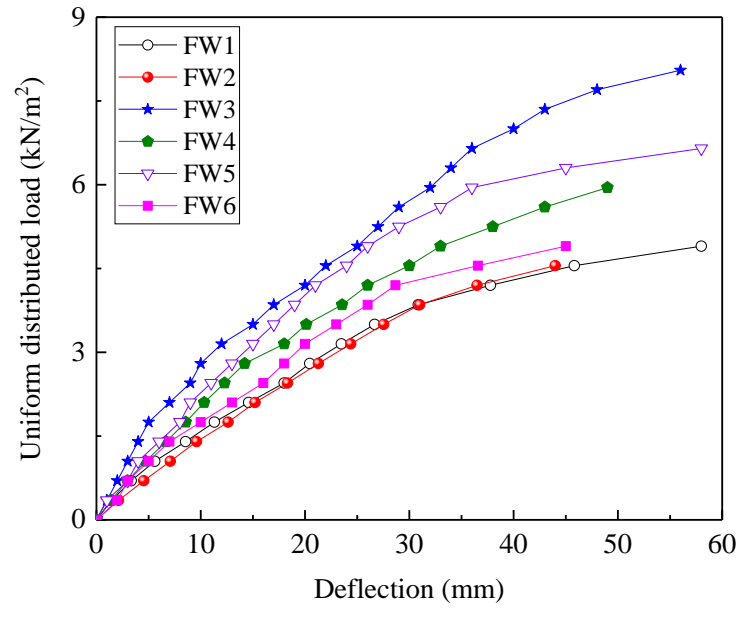

(a) Load-deflection curves at mid-span

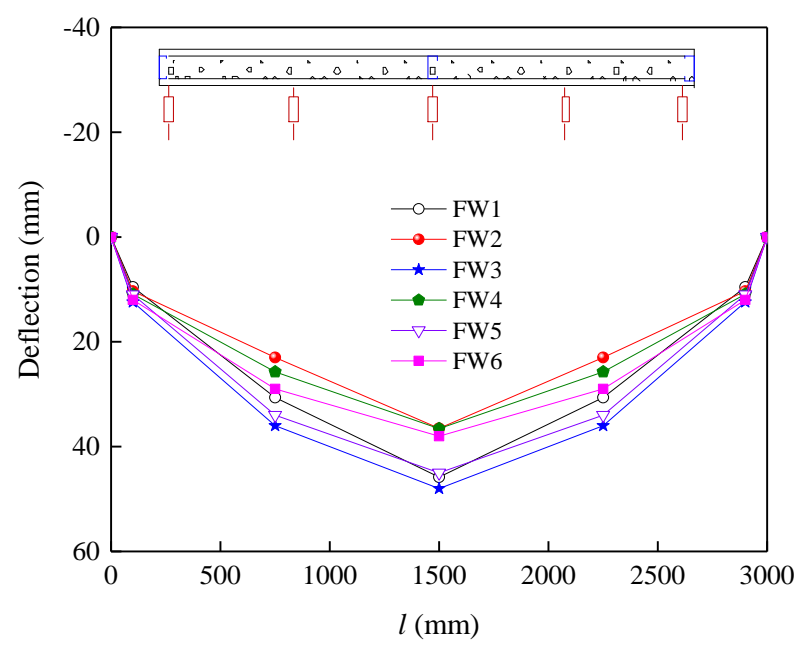

(b) Deflection along the longitudinal direction

Fig. 11 Load-deflection curves of specimens

\section{Cyclic behaviour of LEM-infilled CFS walls}

\subsection{Test specimen}

Six full-scale LEM-infilled CFS wall were designed and tested subjected to cyclic loads [4], considering the influences of LEM types, sheathing types, wall openings, and X-shaped bracing. The detail size and configurations of each specimen are illustrated in Table 5 and Fig. 12. All specimens were $2.755 \mathrm{~m}$ high and $3.00 \mathrm{~m}$ wide, and the wall studs of no opening specimens were all spaced at 600 $\mathrm{mm}$. A hold-down was arranged in each corner of wall with the aim to enhance the end track-to-stud connections. 
Wang et al., SUST, 2022, 2(1): 000013

Table 5. Detail information of specimens [4]

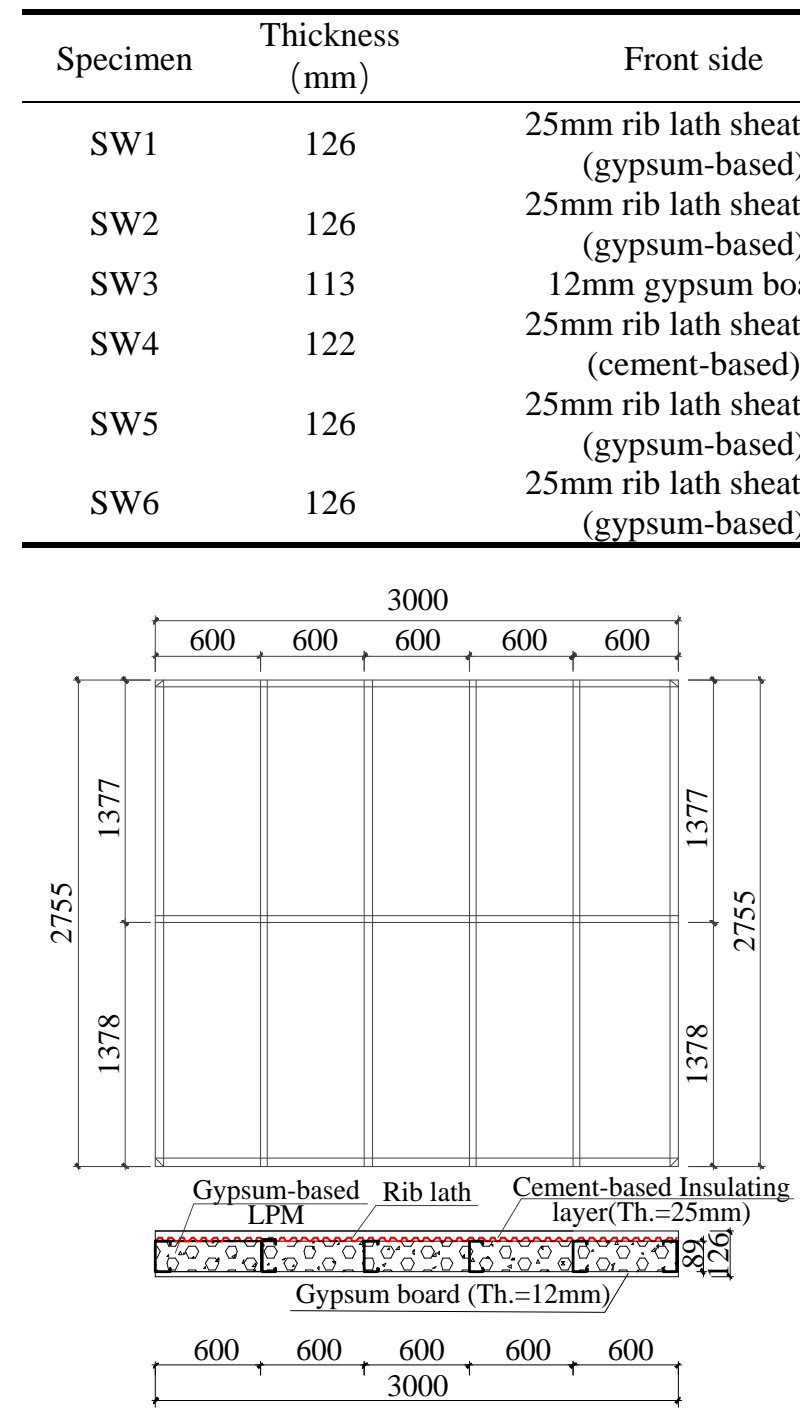

(a) Specimen SW1

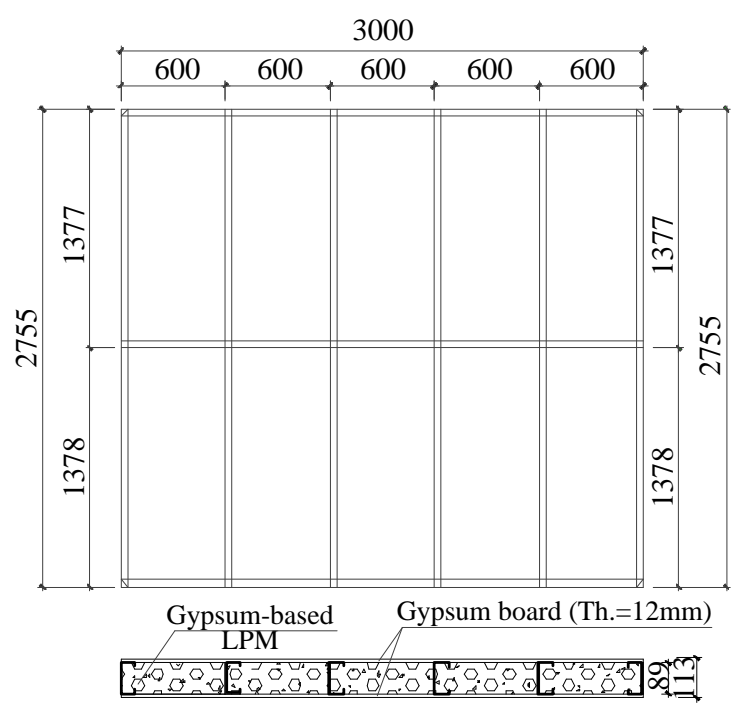

$\begin{array}{r}600,600,600,600,600 \\ \hline\end{array}$

(c) Specimen SW3

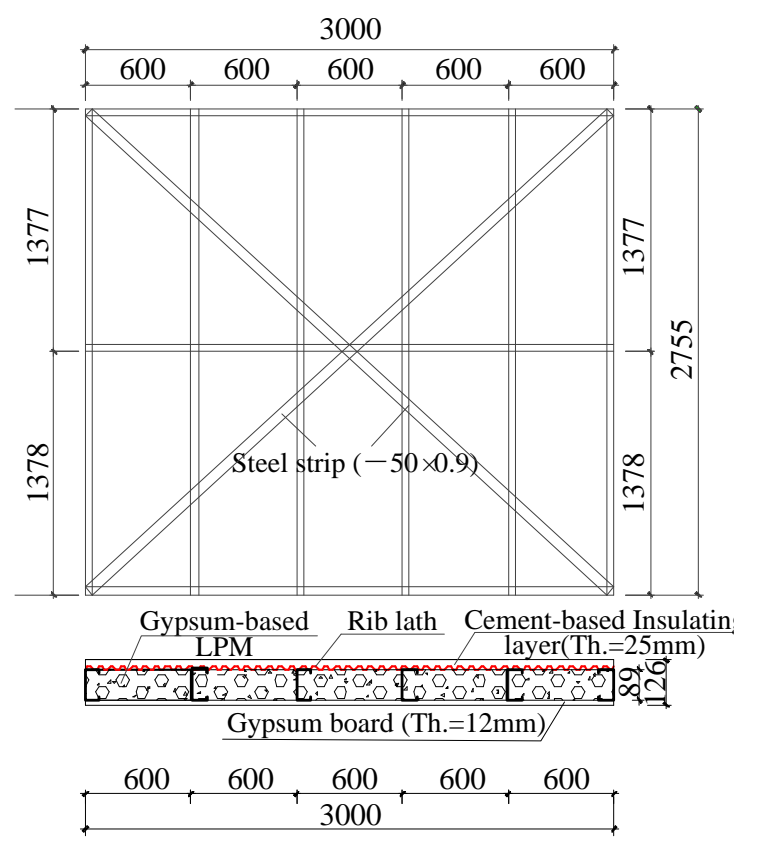

(b) Specimen SW2

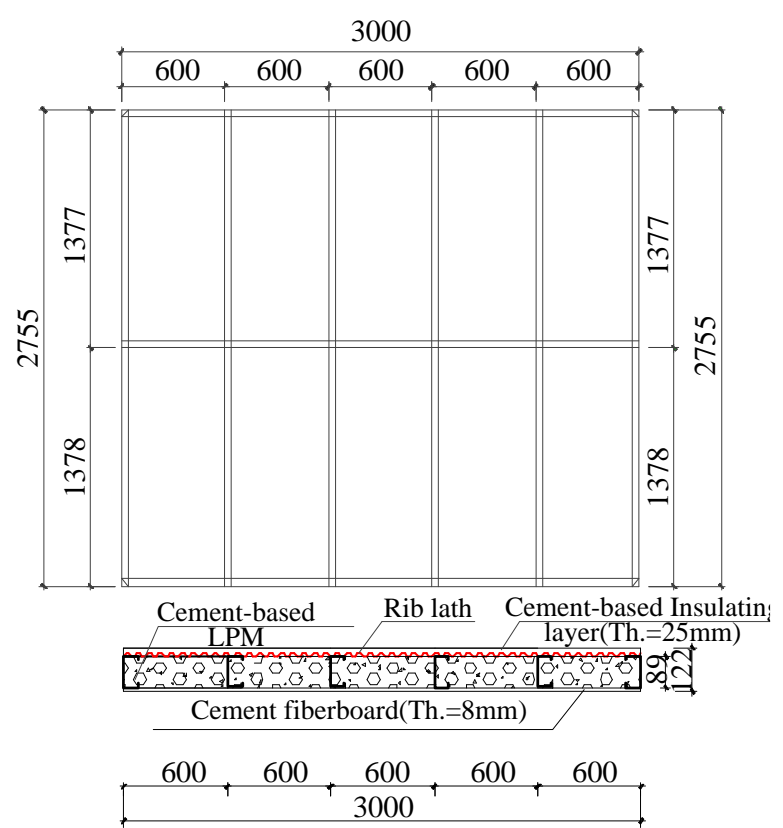

(d) Specimen SW4 


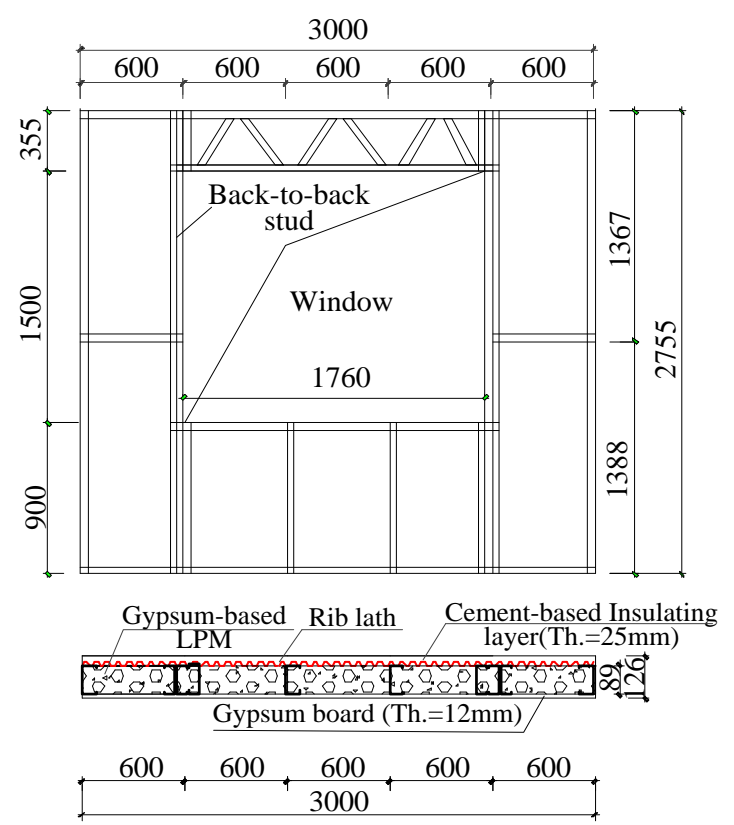

(e) Specimen SW5

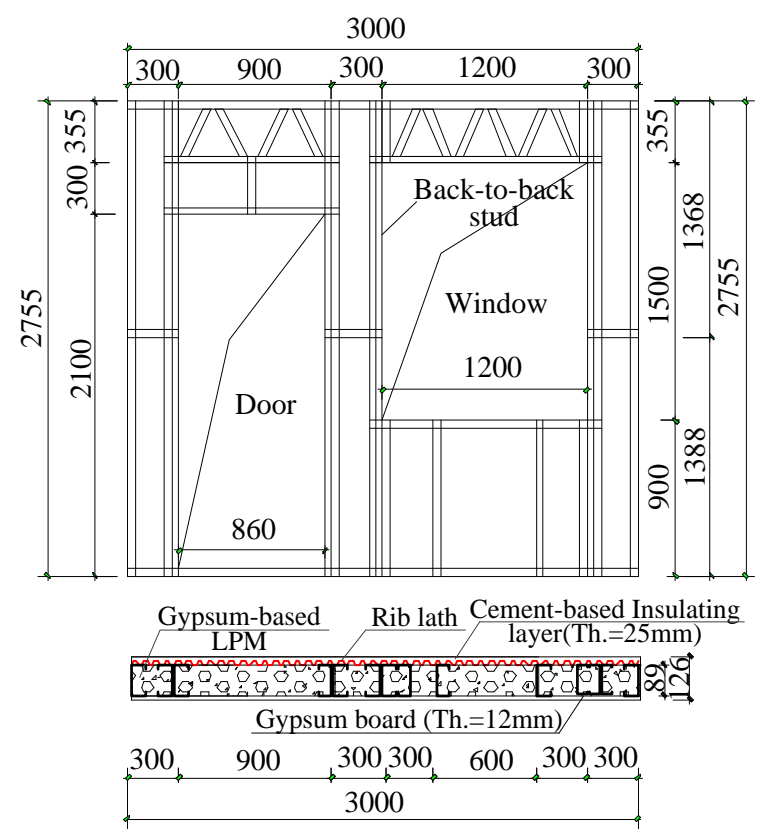

(f) Specimen SW6

Fig. 12 Detail of specimen dimensions [4].

\subsection{Test setup and procedure}

Fig. 13 depicts the test setup of the experiments. All specimens were connected to distributed guider and bottom foundation beam by the embedded anchor bolts. The loading was controlled by displacement and the loading procedure was employed in accordance with ATC-24 [32].

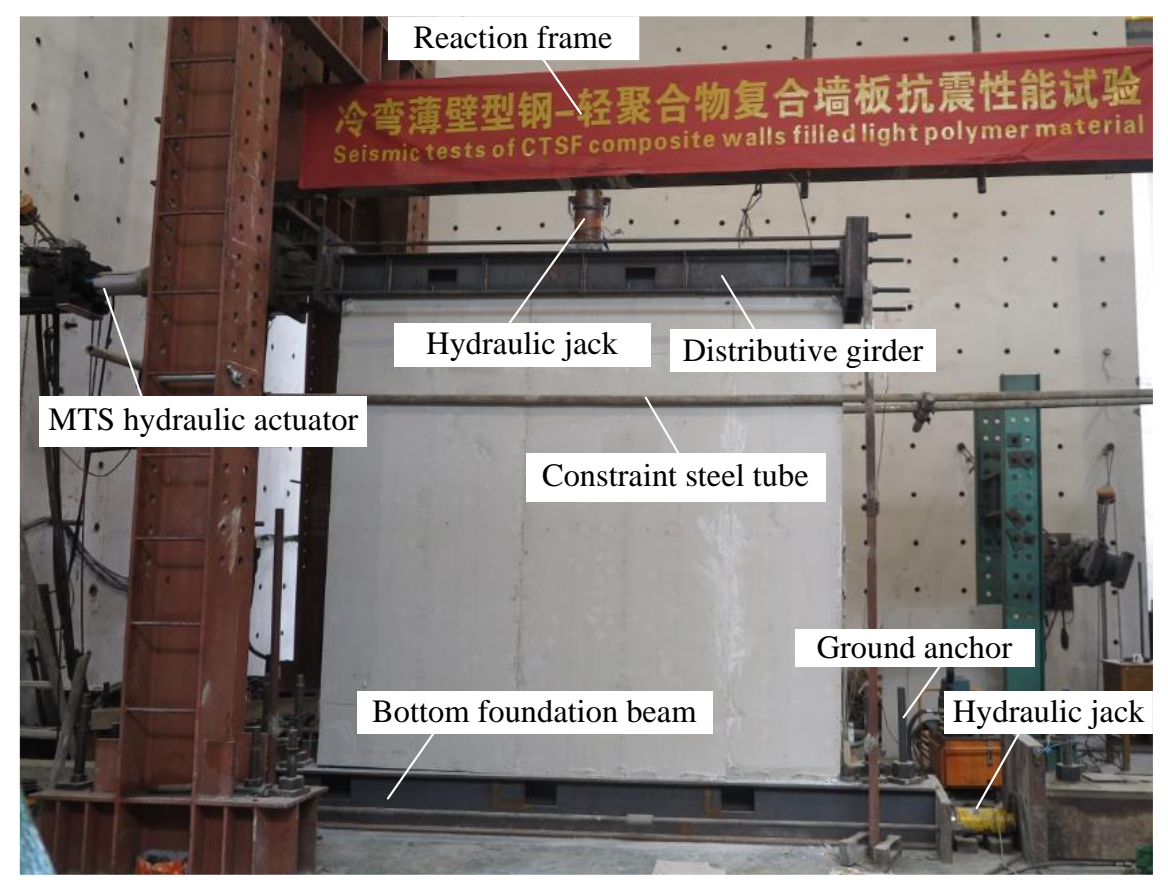

Fig. 13 Test setup of cyclic test

\subsection{Test results}

The failure patterns of LEM-infilled CFS wall mainly included the local buckling of the wall studs, crushing of the LEM, titling of self-drilling screws, and shedding of the wall sheathings. Besides, the $\mathrm{X}$-shaped bracing of specimen SW2 relaxed resulting in the shedding of wall panel. Regarding for the 
specimens with opening, serious buckling of studs was noticed in the edge of openings and the shedding appeared on wall sheathings around the opening corner. Fig. 14 shows the typical failure patterns of specimens.
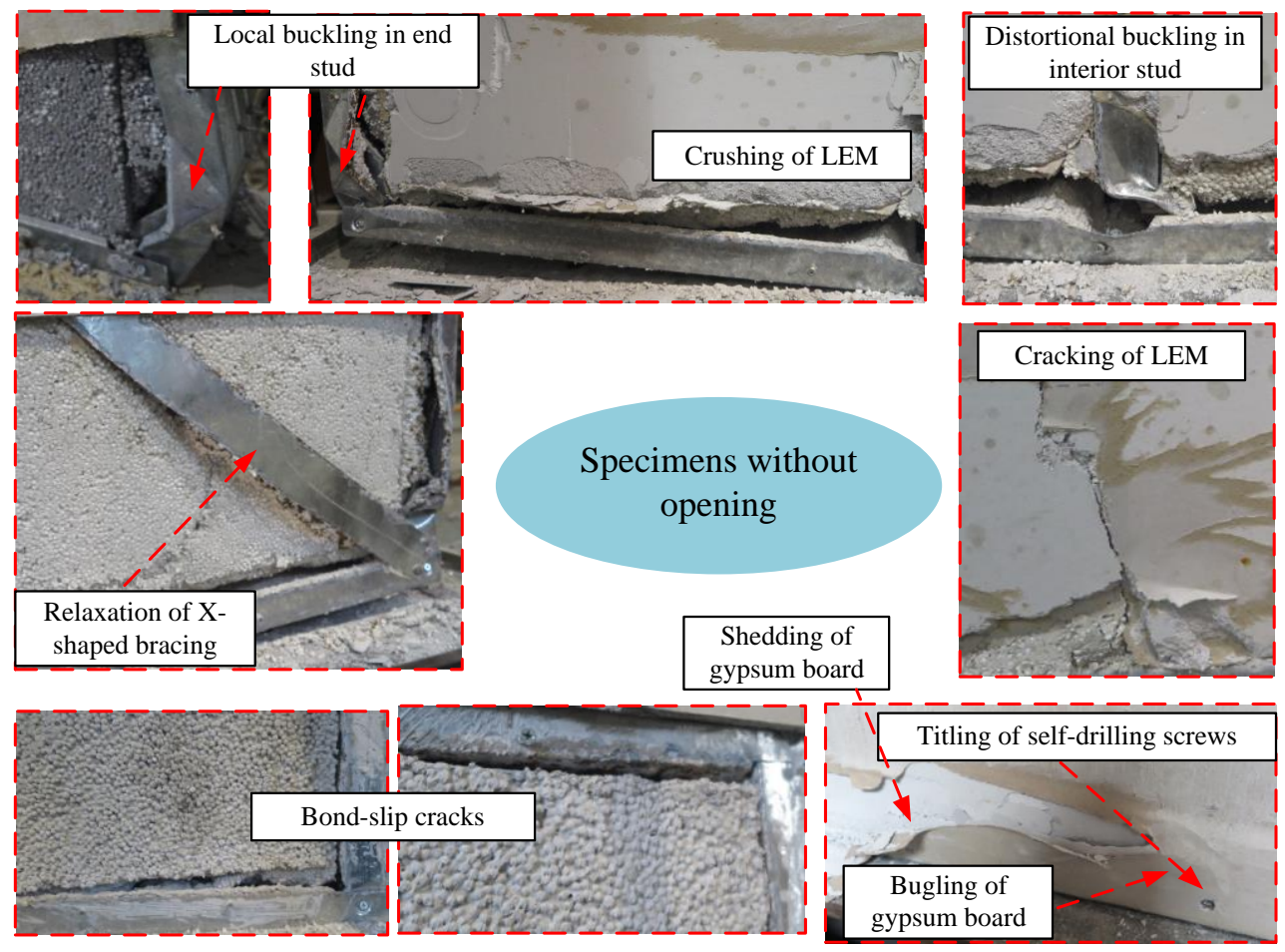

(a) Specimens without openings

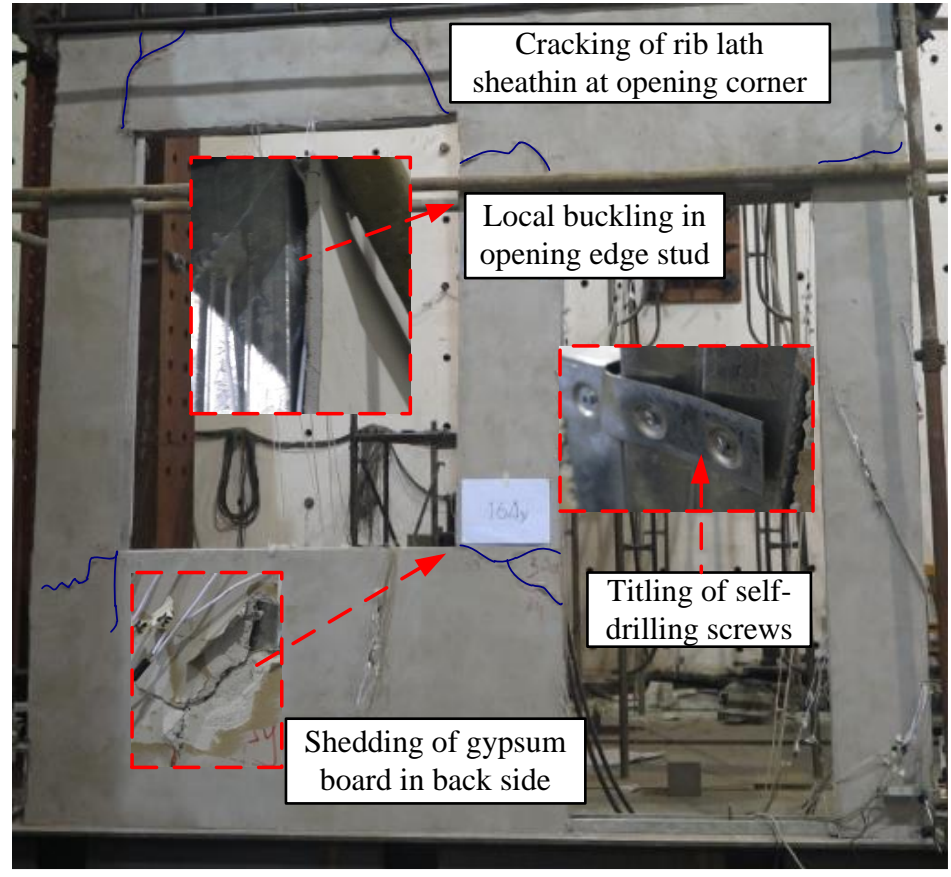

(b) Specimens with openings

Fig. 14 Typical failure modes of specimens under cyclic loading [4].

Fig. 15 shows the hysteresis and envelop curves of all specimens. As the load increasing, the hysteresis curves showed obvious pinching. With respect to traditional CFS wall, this type of wall appeared much better elastic stiffness and capacity. It demonstrated that the LEM and CFS framing could work together to resist the shear force. The CFS wall infilled cement-based LEM had higher load resistance and lateral stiffness than specimens infilled gypsum-based LEM. Besides, compared 
specimens SW2 and SW1, it could be observed that the load resistance and stiffness of the LEM-infilled CFS walls can be effectively increased by the X-shaped bracing. And the comparison between specimens SW1 and SW3 showed that the rib lath sheathing had positive effect on the wall performance. Conversely, the wall openings would descent the stiffness and load resistance of LEM-infilled CFS walls significantly. The test phenomenon showed that severe failures occurred at the opening edge, so some strengthen measures need to be set for walls with opening.

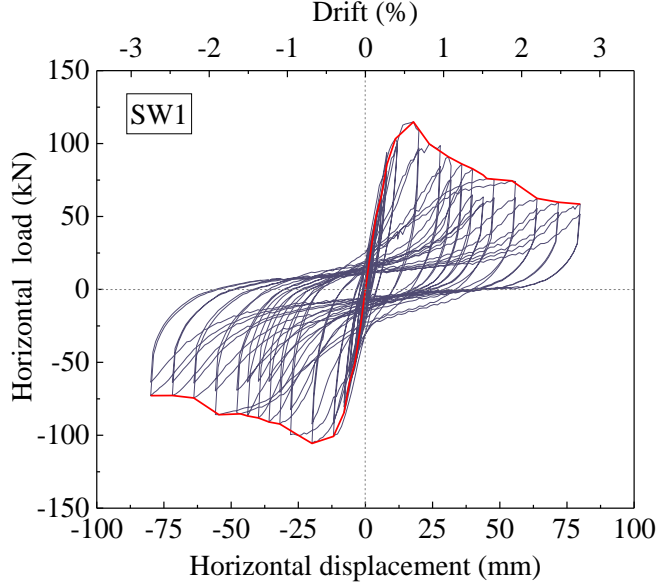

(a) Specimen SW1

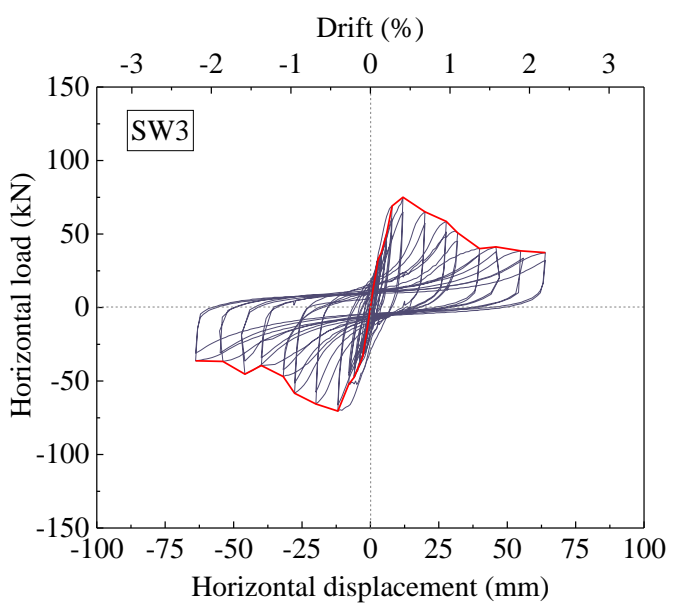

(c) Specimen SW3

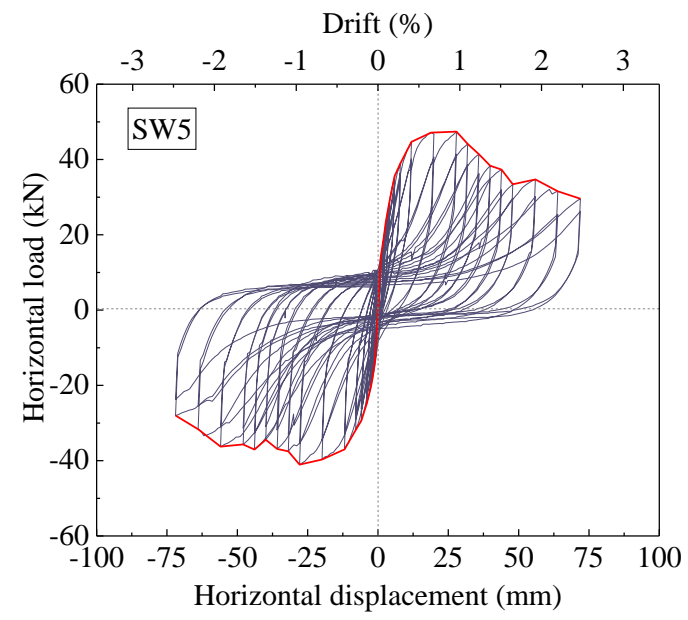

(e) Specimen SW5

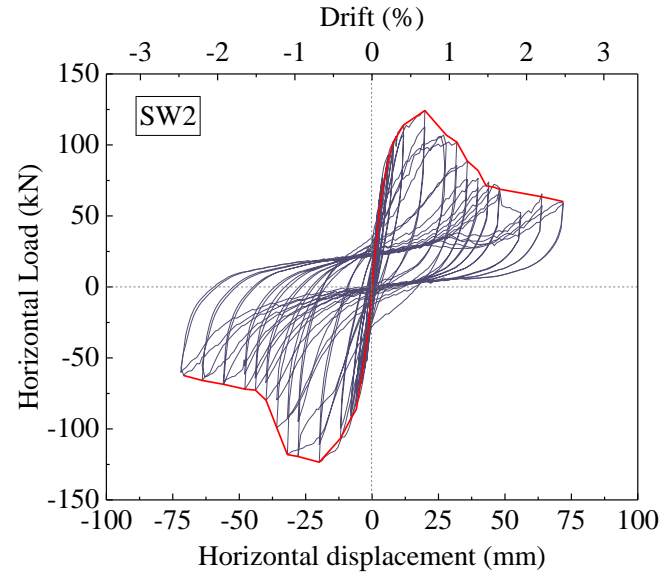

(b) Specimen SW2

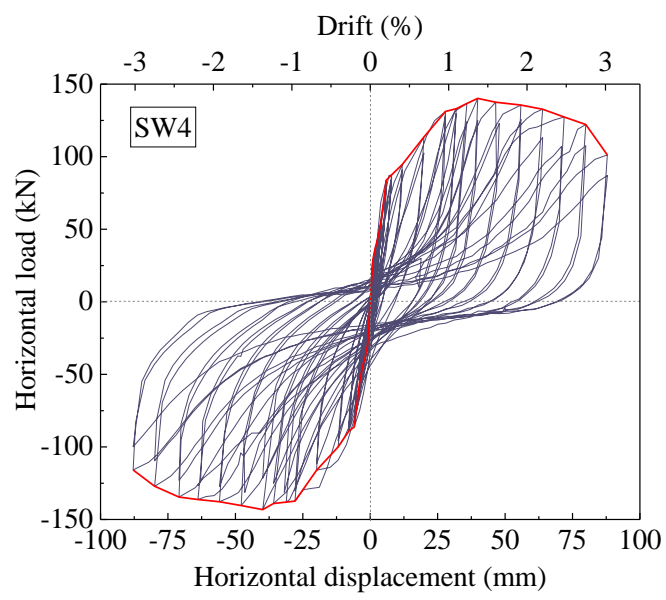

(d) Specimen SW4

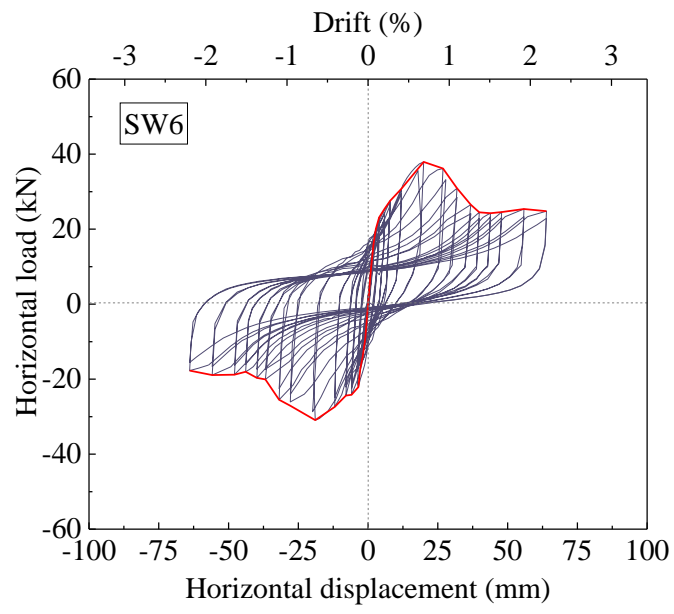

(f) Specimen SW6

Fig. 15 Hysteresis curves of the specimens [4].

Because that there is no relevant specification can be used to evaluate whether the ductility of LEM-infilled CFS walls meet the design requirement, the test results in this paper are compared to other 
studies, such as Wang and Ye [33]. The results indicate that this type of walls had great ductility. Moreover, the LEM-infilled CFS walls also appear excellent energy dissipation capacities. Consequently, the LEM-infilled CFS wall exhibited significant cyclic response, and it is a good selection for earthquake engineering applications.

In addition, the energy dissipation capacities were analyzed. The specimens stayed in the elastic stage before yielding, and there was almost no residual deformation after unloading. Thus, the cumulative energy dissipation was nearly zero. With the increase of loading cycles and lateral displacement, the specimen reached the elastic-plastic stage, and the cumulative energy dissipation increased. The equivalent viscous coefficient and cumulative dissipated energy of the peak load stage and ultimate stage are calculated and listed in Table 6. Compared to specimen SW1, specimen SW2 dissipated $8.13 \%$ and $5.52 \%$ more energy in peak load stage and ultimate stage, respectively. It can be known that the $\mathrm{X}$-shaped bracing act a beneficial effect on the energy dissipation capacity. The existing studies on the traditional CFS wall had proved that the X-shaped bracing can significantly improve the energy dissipation capacity, but the results in this paper showed that the improvement was not obvious. It can be explained by the fact that the LEM filled had provided strong lateral support for the CFS framing, which decreased the important proportion of the X-shaped bracing. Besides, the energy dissipation of specimen SW1 were respectively $75.13 \%$ and $180.30 \%$ higher in peak load stage and ultimate stage than specimen SW3, which demonstrated that rib lath sheathing had a great improvement effect. Conversely, the wall opening can reduce the energy dissipation, and the energy dissipation capacity was decreased with the increase of opening ratio. Moreover, the equivalent viscous coefficients in ultimate stage were $0.19 \sim 0.27$, which could illustrated that the LEM-infilled CFS walls appeared excellent energy dissipation capacity.

Table 6. The energy dissipation of specimens

\begin{tabular}{ccccc}
\hline Specimen & \multicolumn{2}{c}{ Peak load stage } & \multicolumn{2}{c}{ Ultimate stage } \\
& $\begin{array}{c}\text { Cumulative dissipated } \\
\text { energy } W_{\text {total }}\left(\times 10^{2} \mathrm{~J}\right)\end{array}$ & $\begin{array}{c}\text { Equivalent viscous } \\
\text { coefficient } \xi_{\mathrm{e}}\end{array}$ & $\begin{array}{c}\text { Cumulative dissipated } \\
\text { energy } W_{\text {total }}\left(\times 10^{2} \mathrm{~J}\right)\end{array}$ & $\begin{array}{c}\text { Equivalent viscous } \\
\text { coefficient } \xi_{\mathrm{e}}\end{array}$ \\
\hline S-W1 & 81.54 & 0.16 & 292.37 & 0.26 \\
S-W2 & 88.17 & 0.18 & 308.54 & 0.22 \\
S-W3 & 46.56 & 0.14 & 104.31 & 0.18 \\
S-W4 & 334.71 & 0.21 & 1032.17 & 0.19 \\
S-W5 & 59.17 & 0.17 & 159.44 & 0.20 \\
S-W6 & 50.31 & 0.22 & 117.4 & 0.27 \\
\hline
\end{tabular}

\section{Conclusion}

The LEM prepared by using waste desulfurization gypsum and EPS as basic ingredients has great potential to be used as a worthy alternative structural material. Based on the studies, it was proved that the LEM can improve the mechanical performances of CFS wall and restrict the deformation of CFS components.

The reliability of LEM-infilled CFS structure is depended not only on requirements of comfortability, thermal insulation and fire resistance, but also on the safety during a long time of natural condition. Therefore, the mechanical behaviour of LEM-infilled CFS wall under various types of loads were studied, and the influencing factors were considered and discussed. Comparison analysis demonstrates that LEM-infilled CFS wall exhibit excellent compressive, out-of-plane flexural and cyclic responses. The test results also indicate that LEM can work well combined with CFS framing to resist force and strengthen the capacity of CFS wall.

The existing researches are scattered, so further researches, such as the influence of LEM on the wall sheathing-CFS framing connection, are needed to form a series of systematic design method. Besides, the fire retardant treatments of LEM and influence of processing methods on its mechanical and physical properties is a very interesting topic.

\section{Funding Statement}


Financial support is gratefully acknowledged. This study was supported by Introduction Plan of High-level Foreign Experts (Grant No. G20190012003), and the Fundamental Research Funds for the Central Universities of China (Grant No. PA2021KCPY0031).

\section{Conflicts of Interest}

The authors declare no conflict of interest.

\section{Reference}

[1] Liu B, Hao JP, Zhong WH, Wang H. Performance of cold-formed-steel-framed shear walls filled with lightweight mortar under reversed cyclic loading. Thin-Walled Struct 2016; 98: 312-331. https://doi.org/10.1 016/j.tws.2015.09.024.

[2] Wu HH, Chao SS, Zhou TH, Liu XB. Cold-formed steel framing walls with infilled lightweight FGD gypsum Part I: Cyclic loading tests. Thin-Walled Struct 2018; 132: 759-770. https://doi.org/10.1016/j.tws.2018.04.0 03.

[3] Xu ZF, Chen ZF, Yang SH. Seismic behavior of cold-formed steel high-strength foamed concrete shear walls with straw boards. Thin-Walled Struct 2018; 124: 350-365. https://doi.org/10.1016/j.tws.2017.12.032.

[4] Wang WQ, Wang JF, Yang TY, Guo L, Song HH. Experimental testing and analytical modeling of CFS shear walls filled with LPM. Structures 2020; 27: 917-933. https://doi.org/10.1016/j.istruc.2020.06.016.

[5] Wang WQ, Wang JF, Guo L, Shen QH. Seismic response investigation and analytical model of light polymer material filled CFS shear walls. Arch Civ Mech Eng 2020; 20:59. https://doi.org/10.1007/s43452-02000057-7.

[6] Wang WQ, Wang JF, Zhao P, Ja LL, Pan GD. Axial compressive experiments and structural behaviour estimation of CFS composite walls sprayed with LPM. J Build Eng 2020; 30: 101305. https://doi.org/10.101 6/j.jobe.2020.101305.

[7] Wang JF, Pang S, Lu MM, Qiu DH. Experimental study on the flexural behavior of precast cold-formed thinwalled steel framing (CTSF) composite walls infilled with light polymer material, Progress in Steel Building Structures 2018; 20(2): 20-27. (in Chinese) https://doi.org/10.13969/j.cnki.cn31-1893.2018.02.003.

[8] Annual Report on Prevention and Control of Solid Waste in China's Large and Medium-Sized Cities. https://www.sohu.com/a/209141737_682451。

[9] Cook DJ, Swamyr N. Expanded polystyrene concrete, concrete technology and design. London: Surrey University Press, 1983: 41-69.

[10] Babu KG, Babu DS. Behaviour of lightweight expanded polystyrene concrete containing silica fume. Cement Concrete Res 2003; 33(5): 755-762. https://doi.org/10.1016/S0008-8846(02)01055-4.

[11] Daniel Ronald Joseph J, Prabakar J, Alagusundaramoorthy P. Experimental studies on through-thickness shear behavior of EPS based precast concrete sandwich panels with truss shear connectors. Composites Part B. 2019; 166: 446-456. https://doi.org/10.1016/j.compositesb.2019.02.030.

[12] Mousavi SA, Zahrai SM, Bahrami-Rad A. Quasi-static cyclic tests on super-lightweight EPS concrete shear walls. Eng Struct 2014; 65: 62-75. https://doi.org/10.1016/j.engstruct.2014.02.003

[13] Cui CC. Stress-strain relationship in axial compression for EPS concrete. Constr Build Mater 2016; 105: 377-383. https://doi.org/10.1016/j.conbuildmat.2015.12.159。 .

[14] Wu S, Wang WL, Ren CZ, Yao XL, Yao YG, Zhang QS, Li ZF. Calcination of calcium sulphoaluminate cement using flue gas desulfurization gypsum as whole calcium oxide source, Constr Build Mater 2019; 228: 116676.A. https://doi.org/10.1016/j.conbuildmat.2019.116676.

[15] Zhang YJ, Pan F, Wu R. Study on the performance of FGD gypsum-metakaolin-cement composite cementitious system. Constr Build Mater 2016; 128: 1-11. https://doi.org/10.1016/j.conbuildmat.2016.09. 134.

[16] Koralegedara NH, Pinto PX, Dionysiou DD, Al-Abed SR. Recent advances in flue gas desulfurization gypsum processes and applications - A review, J Environ Manage 2019; 251: 109572. https://doi.org/10.101 6/j.jenvman.2019.109572.

[17] Liang RF, Stanislawski D, Hota G. Material characterization and structural response under earthquake loads of hakka rammed earth buildings. Sustain Struct 2021; 1(1): 000003. https://doi.org/10.54113/j.sust.2021. 000003.

[18] Shakeela S, Fiorinob L, Landolfo R. Behavior factor evaluation of CFS wood sheathed shear walls according to FEMA P695 for Eurocodes. Eng Struct 2020; 221: 111042. https://doi.org/10.1016/j.engstruct.2020. 111042.

[19] Schafer BW, Ayhan D, Leng J, Liu P, Padilla-Llano D, Peterman KD. Seismic response and engineering of cold-formed steel framed buildings. Structures 2016; 8: 197-212. https://doi.org/10.1016/j.istruc.2016.05. 009. 
[20] Fiorino L, Macillo V, Landolfo R. Shake table tests of a full-scale two-story sheathing-braced cold-formed steel building. Eng Struct 2017; 151: 633-647. https://doi.org/10.1016/j.engstruct.2017.08.056.

[21] Fiorino L, Bucciero B, Landolfo R. Shake table tests of three storey cold formed steel structures with strap braced walls. B Earthq Eng 2019; 17(7): 4217-4245. http://doi.org/10.1007/s10518-019-00642-z.

[22] Nithyadharan M, Kalyanaraman V. A new screw connection model and FEA of CFS shear wall panels. J Constr Steel Res 2021; 176: 106430. https://doi.org/10.1016/j.jcsr.2020.106430.

[23] Wang XX, Ye JH, Yu Q. Improved equivalent bracing model for seismic analysis of mid-rise CFS structures. J Constr Steel Res 2017; 136: 256-264. https://doi.org/10.1016/j.jcsr.2017.05.013.

[24] Tapia JV. The development of novel infill materials for composite structural assemblies (Master thesis), Auckland University of Technology (AUT), 2013.

[25] Oluokun F. Prediction of concrete tensile strength from its compressive strength: an evaluation of existing relations for normal weight concrete, ACI Mater. J. 88 (3) (1991) 302-309.

[26] C.E.B.F.I.P. MC90, Design of Concrete Structures. CEB-FIP Model Code 1990, Thomas Telford, London, 1993.

[27] Formisano A, Mazzolani FM, De Matteis G. Numerical analysis of slender steel shear panels for assessing design formulas. Int J Struct Stab Dy 2007; 7(2): 273-294. https://doi.org/10.1142/S0219455407002289.

[28] Amran YHM, Farzadnia N, Abang Ali AA. Properties and applications of foamed concrete: a review. Constr Build Mater 2015; 101: 990-1005. https://doi.org/10.1016/j.conbuildmat.2015.10.112.

[29] Vieira LCM, Schafer BW. Behavior and design of sheathed cold-formed steel stud walls under compression. J Struct Eng 2013; 139 (5): 772-786. https://doi.org/10.1061/(ASCE)ST.1943-541X.0000731.

[30] Vieira LCM, Shifferaw Y, Schafer BW. Experiments on sheathed cold-formed steel studs in compression. J Constr Steel Res 2011; 67: 1554-1566. https://doi.org/10.1016/j.jcsr.2011.03.029.

[31] Zhang XH, Zhang EY, Li CR. Study on axial compression mechanical behavior of cold-formed thin-walled C-shaped steel composite wall sheathed with straw board on both sides. Structures 2021; 33: 3746-3756. https://doi.org/10.1016/j.istruc.2021.06.071.

[32] ATC-24. Guidelines for cyclic seismic testing of components of steel structures. Redwood City (CA): Applied Technology Council; 1992. https://doi:10.1016/j.tws.2007.02.017.

[33] Wang XX, Ye JH. Cyclic testing of two- and three-story CFS shear-walls with reinforced end studs. J Constr Steel Res 2016; 121: 13-28. https://doi.org/10.1016/j.jcsr.2015.12.028. 